\title{
Heteropsis reticulata (Araceae): complementação da descrição e novo registro para o estado do Mato Grosso, Brasil
}

\author{
Heteropsis reticulata (Araceae): description complements \\ and new record for the Mato Grosso state, Brazil
}

Lilien Cristhiane Ferneda Rocha ${ }^{1,3}$ \& Mathias Erich Engels ${ }^{2}$

\begin{abstract}
Resumo
Durante o resgate de Flora da usina Hidrelétrica Colíder foi coletado material de Heteropsis reticulata em todas as suas fases fenológicas, possibilitando ampliar o conhecimento desta espécie, até o momento apenas conhecida pelo material tipo herborizado. Este corresponde a um novo registro de distribuição geográfica para a região Centro Oeste, no estado do Mato Grosso.

Palavras-chave: Amazônia, hemiepífita, Monsteroideae, região neotropical, Rio Teles Pires.
\end{abstract}

\begin{abstract}
During the flora rescue of Hydroelectric Power Plant of Colíder, material of Heteropsis reticulata was collected in all phenological phases, it allow us to increase knowledge of this species, until now it was known just by the type herborized material. This is also a new record of geographical distribution to Central-West region in the Mato Grosso state.
\end{abstract}

Key words: Amazon, hemiepiphyte, Monsteroideae, Neotropics, Teles Pires River.

O gênero neotropical Heteropsis Kunth possui 18 espécies com centro de diversidade na Amazônia sul americana, sendo representado por ervas hemiepífitas (Soares et al. 2013). No Brasil, ocorrem 15 espécies, distribuídas desde a região sul até a região norte em áreas de Mata Atlântica, Cerrado e Floresta Amazônica (BFG 2015).

Apesar de ser um gênero de fácil reconhecimento, a delimitação das espécies é especialmente morosa pela proximidade e sobreposição das características distintivas. Além disso, devido à forma de vida hemiepífita, com ramos atingindo normalmente do sub-bosque até o dossel e inflorescências e frutos pouco conspícuos, torna-se difícil a visualização de indivíduos férteis na natureza, acarretando na subamostragem do grupo e sua pouca representatividade em coleções botânicas (Soares et al. 2013).

Durante o resgate de Flora da Usina Hidrelétrica de Colíder, nos municípios de Colíder, Claudia, Itaúba e Nova Canaã do Norte, estado do Mato Grosso, foi coletado material fértil de Heteropsis reticulata Croat \& M.L.Soares. Devido à abundância da espécie na área do empreendimento, foi possível realizar coletas de qualidade com material em suas diferentes fases fenológicas, permitindo a análise de suas características em material fresco e ampliando o conhecimento taxonômico e ecológico deste táxon conhecido apenas pelas exsicatas do material tipo. Também foi possível registrar pela primeira vez a espata, cor de fruto e fotografar o material fresco, além de apresentar dados ecológicos da espécie.

\section{Tratamento taxonômico}

Heteropsis reticulata Croat \& M.L.Soares, Systematic Botany 38(4): 956, 2013. Tipo: BRASIL. Acre: Cruzeiro do Sul, próximo ao aeroporto, 13.II.1976, fr., Monteiro \& Damião 349 (holótipo: INPA).

Fig. 1

Erva hemiepífita escandente; ramo secundário $11,2-26(-52) \times 0,1-0,3 \mathrm{~cm}$, subcilíndrico, aplanado em um dos lados do entrenó, estriado quando seco, gemas axilares presentes, entrenós 1,2-3,2 cm

\footnotetext{
${ }^{1}$ Juris Ambientis Consultores S S Ltda., R. Humberto Carta 96, Hugo Lange, 80040-150, Curitiba, PR, Brasil.

${ }^{2}$ Assessoria Técnica Ambiental Ltda., R. Marechal José Bernardino Bormann 821, Batel, 80730-350, Curitiba, PR, Brasil.

${ }^{3}$ Autor para correspondência: liliencristhiane@gmail.com
} 


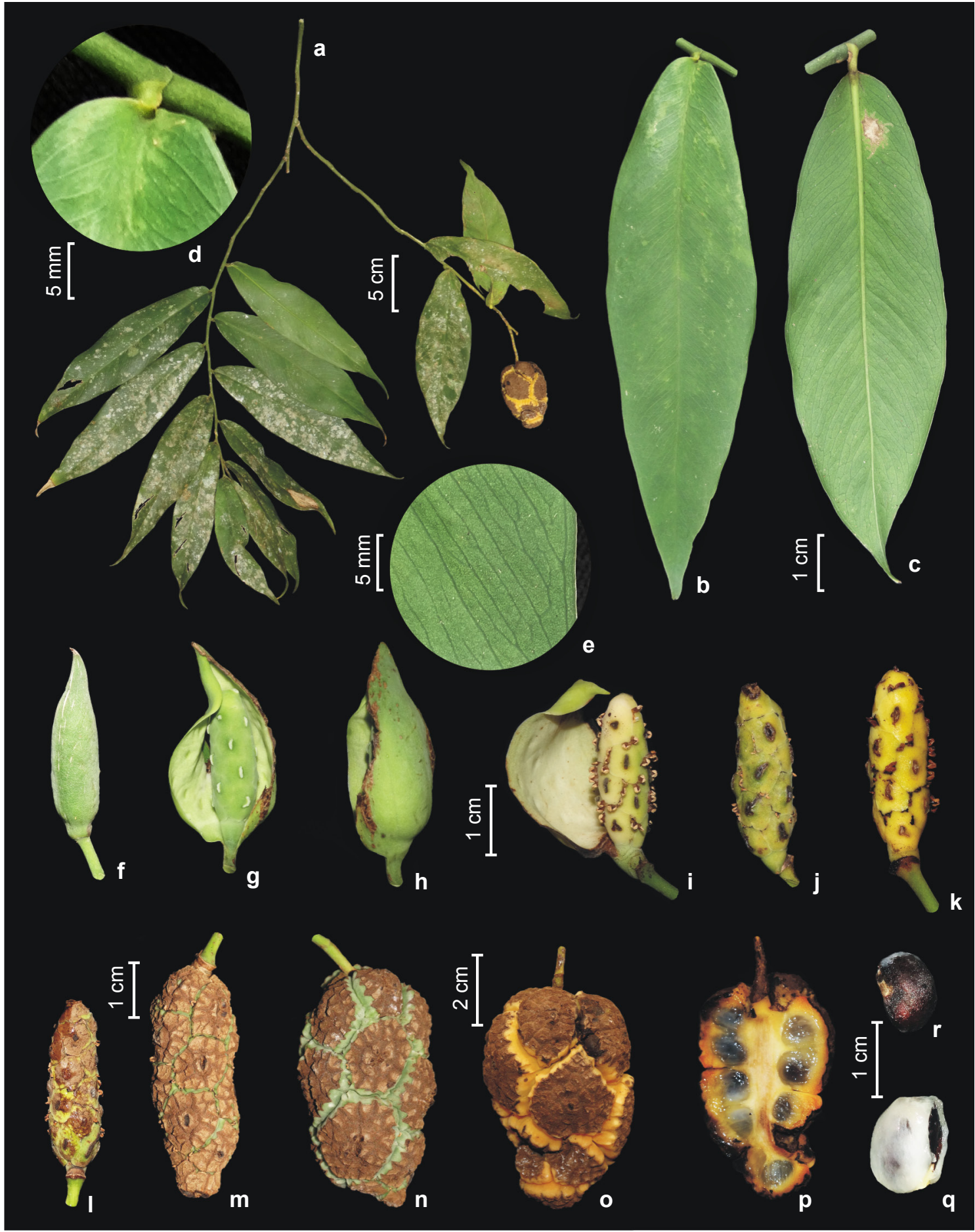

Figura 1 - Heteropsis reticulata - a. hábito; b-e. folha - b. face adaxial; c. face abaxial; d. detalhe da base; e. detalhe das nervuras; f-1. inflorescência - f. pré antese; g-h. em antese, fase feminina; i-k. em antese, fase masculina; i. com espata ainda presente; j,k. espádice após queda da espata; l. espádice pós antese, iniciando frutificação; m. fruto jovem; $n$. fruto desenvolvido imaturo; o. fruto maduro; p. fruto maduro em corte; q-r. semente - q. semente com poupa envolvendo. Figure 1 - Heteropsis reticulata - a. habit; b-e. leaf. b. adaxial face; c. abaxial face; d. detail of base; e. detail of veins; f-l. Inflorescence, f. pre anthesis; g-h. in anthesis, female phase; i-k. in anthesis, male phase; i. with spathe; j-k, spadix after deiscence of spathe; 1 . spadix pos anthesis, starting fruiting; $\mathrm{m}$. young fruit; $\mathrm{n}$. fruit developed immature; $\mathrm{o}$. mature fruit; $\mathrm{p}$. section of mature fruit; $\mathrm{q}-\mathrm{r}$. seed; $\mathrm{q}$. seed with pulp involving. 
compr. Folhas com pecíolo 3-6 × 1-2 mm compr., canaliculado, margem ondulada, geniculado; limbo foliar (6,5-)8,7-172 × (1,2-)2,1-5,5 cm, elíptico a oblanceolado, base cuneada a arredondada, margem levemente sinuada e revoluta, ápice acuminado, coriácea, verde discolor; nervura central sulcada na face adaxial, proeminente e arredondada na face abaxial; nervuras laterais primária proeminentes; nervuras laterais interprimárias reticuladas e proeminentes; nervura coletora ca. $1 \mathrm{~mm}$ da margem, proeminente. Inflorescência terminal ou axilar; ramo florífero $(1,5-) 2,7-8,2 \times$ ca. 0,2 $\mathrm{cm}$, subcilíndrico, entrenós $0,5-2,1 \mathrm{~cm}$ compr.; espata $2-3,2 \times 2,2-2,6 \mathrm{~cm}$, ovalada, côncava, margem inteira, ápice acuminado, verde quando imatura, externamente amarelo-claro a verde-claro e internamente alvascente quando madura, decídua durante a antese; espádice 1,6-2,6 × 0,5-0,7 cm, elíptico, cilíndrico, 3-5 espirais, (1-)2-3 flores por espiral, verde-claro, amarelado a alvacento; estípete 1-3× ca. $2 \mathrm{~mm}$, cilíndrico, verde; superfície floral (2-)4-6 mm; anteras ca. $1 \mathrm{~mm}$ compr., elípticas, castanho-paleáceas; estigma 1-2 mm compr., estreito-elíptico. Infrutescência 4,4-9,2 $\times 2,2-3,6 \mathrm{~cm}$, elíptica a oblonga; baga $1,4-2 \mathrm{~cm}$ compr., superfície alveolado-aureolada, castanha, lateralmente verde-azulada quando imatura e amarela quando madura; semente ca. 1,2 $\times 0,7 \mathrm{~cm}$, elípticas a subglobosas, negras, 3-4 por baga; polpa alvo-hialina, recobrindo finamente as sementes.

Material examinado: Itaúba, Resgate de Flora da UHE Colíder, lote C de supressão, 10.XI.2014, fr., M.E. Engels et al. 4239 (HERBAM, MBM, TANG); Lote E de supressão, 20.II.2015, fl. e fr., M.E. Engels 2766 (CNMT, HERBAM, MBM, TANG, RB); 20.II.2015, fl. e fr., M.E. Engels 2767 (CNMT, HERBAM, MBM, TANG, RB); Lote $\mathrm{G}$ de supressão, 29.I.2015, fr., A.Z. Bronholi eq. 11237 (HERBAM, MBM). Nova Canaã do Norte, Resgate de Flora da UHE Colíder, lote A de supressão, 24.XI.2014, fl., M.E. Engels 4237 (CNMT, HERBAM, MBM, TANG, RB); 29.XI.2014, fl., M.E. Engels 4238 (MBM).

Heteropsis reticulata ocorre no Perú e no Brasil (Soares et al. 2013). No Brasil, até o momento era registrada apenas para o estado do Acre (Soares et al. 2013; BFG 2015), sendo este um novo registro de distribuição geográfica para o estado do Mato Grosso, na região Centro Oeste (Fig. 2).

Hemiepífita abundante nas matas às margens do rio Teles Pires, entre os municípios de Itaúba e Nova Canaã do Norte. Ocorre a cerca de 6 a 9 metros

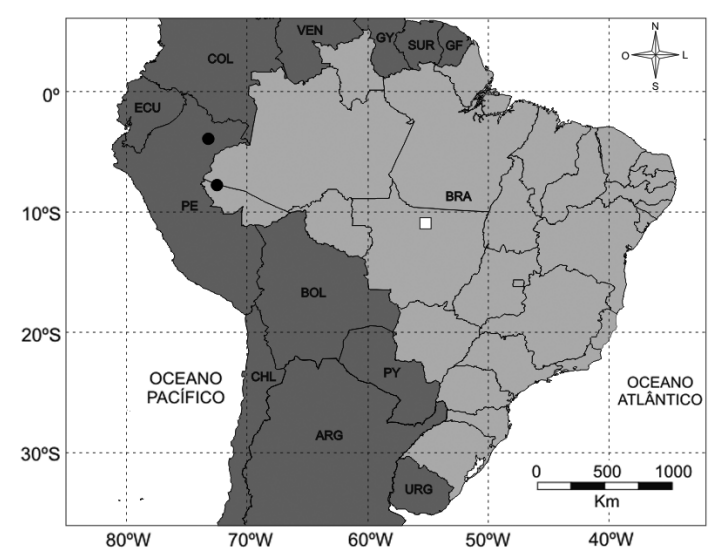

Figura 2 - Mapa de distribuição geográfica de Heteropsis reticulata. Círculos negros correspondem a distribuição conhecida e o quadrado branco o novo registro.

Figure 2 - Geographic distribution map of Heteropsis reticulata. Black circles correspond to the known distribution and the white square the new record.

do solo, normalmente não ultrapassando a altura da copa das árvores do estrato médio. Seus ramos formam touceiras pouco densas. A floração ocorre nos meses de janeiro e fevereiro e a frutificação entre novembro e fevereiro.

Heteropsis reticulata é caracterizada pelo conjunto das seguintes características: folhas elípticas a oblanceoladas, margem revoluta, ápice acuminado, nervuras laterais interprimárias reticuladas; espádice com poucas e grandes flores (3-5 espirais, com 1-3 flores por espiral, superfície floral (2-)4-6 $\mathrm{mm}$ ); frutos com superfície alveolado-aureolada de cor castanha, quando imaturo lateralmente verdeazuladas e quando maduro amarelas.

\section{Agradecimentos}

À Companhia Paranaense de Energia (COPEL) por permitir e encorajar a publicação dos presentes dados; ao Consórcio CIA Ambiental e colaboradores.

\section{Referências}

BFG - The Brazil Flora Group (2015) Growing knowledge: an overview of seed plant diversity in Brazil. Rodriguésia 66: 1085-1113.

Soares ML, Mayo SJ \& Gribel R (2013) A preliminary taxonomic revision of Heteropsis (Araceae). Systematic Botany 38: 925-974. 